\title{
Comportamento de ovoposiçào e cíclo evolutivo de Simulium fulvinotum Cerq. e Melo 1968 (Diptera, Nematocera)
}

\author{
1. S. Gorayeb (")
}

\section{Resumo}

Simulium fulvinotum pela primeira vez foi encontrado na natureza em sua forma adulta e seu criadouro natural foi definido. O comportamento de ovoposição foi descrito e os substratos preferidos para depositar os ovos foram determinados. Os 8 estágios larvais de S. fulvinotum, número de estágios que é encontrado pela segunda vez em Simuliidae, foram determinados por coletas e medidas de pós-genae e do apódema cefá. lico de 548 larvas. O pico de temperatura do dia foi evidenciado como um estímulo para as fêmeas iniciarem as atividades de postura $e$ a intensidade desta atividade foi considerada inversamente relacionada aos valores de luminosid̨de. A duraçăo e o intervalo de horas que a ovoposição ocorre também foram determinados por levantamentos executados com as condiçōes climáticas do criadouro natural da espécie. O periodo de incubação dos ovos foi definido por criação dos mesmos no laboratório. O S . fulvinotum é novamente proposto como um modelo para estudos iniciais de ecologia, biologia e comportamento de Simulium na Amazônia.

\section{INTRODUÇÃo}

Os simulideos, além de transmitirem Oncocercose, Mansonelose e causarem a Síndrome Hemorrágica de Altamira no norte do Brasil (Rassi et al., 1975; Cerqueira, 1959 e Pinheiro et al., 1974, respectivamente), são dipteros importantes pela insistência em atacar o homem à procura de repasto sanguíneo em extensas áreas.

Os trabalhos executados sobre biologia e ecologia de simulídeos no Brasil são poucos e as informaçōes sobre isso estão restritas às citações bionômicas nas descrições das espécies.

O Simulium fulvinotum foi descrito em 1968 por Cerqueira \& Melo, que obtiveram adultos criados de pupas no laboratório, mas nunca havia sido encontrado sob forma adulta na natureza. Gorayeb \& Pinger (1978) elegeram o
S. fulvinotum como um modelo para estudos de ecologia e biologia e detectaram os predadores naturais das larvas. Dellome (1978) descreveu as condições fisico-químicas dos criadouros em que as pupas desta e de outras espécies vivem. Além destes trabalhos não se tem mais informações sobre esta espécie e sua biologia é desconhecida.

O presente trabalho observa as fêmeas adultas, descreve a ovoposição e o criadouro natural da espécie; determina o número de estágios larvais por medidas do comprimento da pós-genae e da distância entre os apódemas cefálicos e apresenta algumas notas biológicas sobre a espécie.

\section{MATERIAL E MÉTODOS}

Freqüentes excursões a um trecho de um igarapé de águas pretas, localizado a $30 \mathrm{~km}$ da cidade de Manaus, Amazonas, Brasil (Fig 1) possibilitaram surpreender as fêmeas de Simulium fulvinotum ovipondo. O igarapé era corrente sob a mata primária, floresta tropical úmida, pouco mexida.

Medidas de luminosıdade, temperatura é umidacie relativa do ar foram tomadas de 30 em 30 minutos em 5 dias, desde 6 até as 18 horas no criadouro da espécie e o número de fêmeas ovidondo foi contado e relacionado com estes dados, na intençāo de perceber a influência destes fatores microclimáticos na atividade de postura. A luminosidade foi medida com um luxímetro e 5 medidas foram tomadas de meia em meia hora em volta do trecho onde as fêmeas faziam a postura, e a média das 5 medidas expressava a luminosidade do horário. A temperatura foi tomada com um termômetro pendurado a $1 \mathrm{~m}$ do chão, nas proximidades do local de postura. A umidade relativa do ar foi obtida com um psicrômetro ao

(*) - Museu Paraense Emilio Goeldi, Belém. 


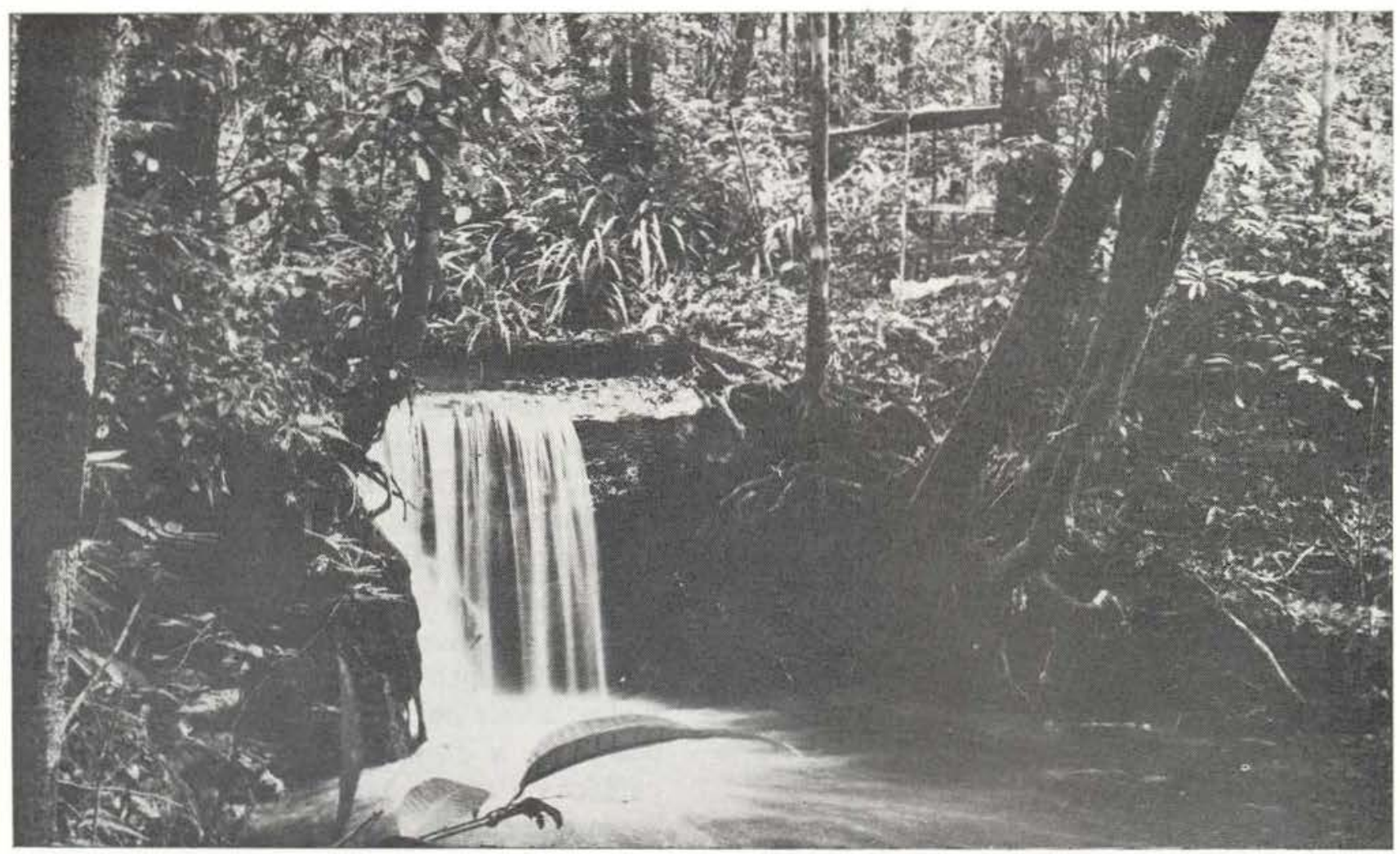

Fig. 1 - Trecho do igarapé de águas pretas onde o estudo foi executado, localizado a $30 \mathrm{~km}$ da cỉdade de Manaus, Amazonas, Brasil.

lado do termômetro. Os dados sobre condutividade elétrica, miligramas de sais dissolvidos por litro, temperatura, $\mathrm{pH}$, taxa de oxigênio e velocidade da água do mesmo trecho estudado do igarapé foram tomados por Dellome (1978).

O comportamento de ovoposição e os substratos preferidos para depositar os ovos foram definidos através de observações das fêmeas em atividades de postura. Substratos com ovos recém-depositados foram colocados em sacos plásticos contendo água do próprio igarapé $\mathrm{e}$ transportados para o laboratório dentro de um vasilhame de isopor com gelo. Os ovos foram mantidos nos sacos plásticos durante 3 horas no máximo. No laboratório, os substratos foram transferidos para um vasilhame de vidro transparente, com água do próprio igarapé e com uma pequena bomba de ar para oxigenar a água. Neste vasilhame os ovos foram observados com microscópio estereoscópico, com aumento de $72 X$, até a eclosão e o tempo de incubaçäo foi determinado. No laboratório a tenperatura variou de 25 a $26^{\circ} \mathrm{C}$ e a umidade relatıva do ar de 70 a $90 \%$.

Larvas de vários tamanhos foram coletadas ncs criadouros e imediatamente depositadas em frascos com álcool $95 \%$. No laboratório, mediu-se o comprimento do corpo, da pósgenae (Fig. 2a) e da distância entre os apódemas cefálicos (Fig. 2b) de 548 larvas, utilizando-se microscópic estereoscópico com ocular micrométrica e aumento máximo de $72 \mathrm{X}$, para determinar o número de estágios larvais pela técnica de Dyar [Apud Wigglesworth, 1972]. As medidas foram colocadas em uma distribuição de freqüência para visualizar o número de estágios larvais (Fig. 3a). Utilizando-se o método do quadrado mínimo, os logarítmos naturais das medidas dos comprimientos das pósgenae e das distâncias entre os apódemas cefálicus das larvas foram confrontadcs com o número dos estágios larvais (Figs. $3 \mathrm{~b}$ e $3 \mathrm{c}$ ). Os dados foram agrupados seguindo-se os procedimentos de Sokal \& Rohif (1969). 

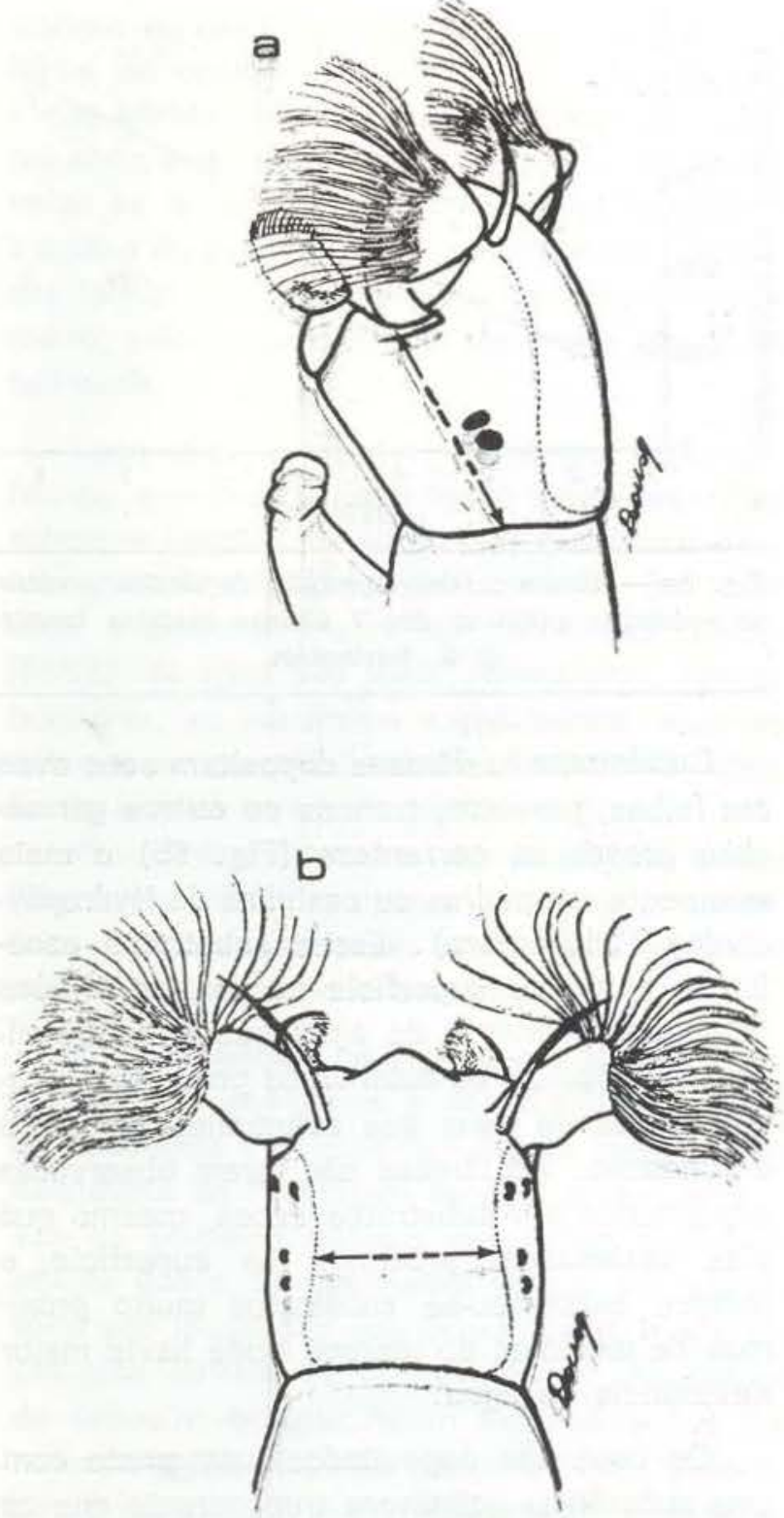

Fig. 2 - Estruturas medidas na cabeça das larvas de S. fulvinotum para determinar o número de estágios. a) pós-genae e b) distância entre os apódemas cefá. licos.

\section{Resultados}

As fêmeas adultas de Simulium fulvinotum foram observadas ovipondo exatamente nos trechos do igarapé onde a correnteza e a turbulência da água eram mais acentuadas por pequenas quedas d'água ou por qualquer obstáculo que se opunha à correnteza. Elas iniciam as atividades de postura quando a luz começa a cair, imediatamente após o pico má- ximo de temperatura do dia e terminam quando a luminosidade aproxima-se de zero (Figs $4 a$, $4 \mathrm{~b}, 4 \mathrm{c}, 4 \mathrm{~d}$ e $4 \mathrm{e})$.

No primeiro dia estudado (2 de abril de 1979 - Fig. 4a), o pico de temperatura foi às 13:30 horas, e imediatamente após as fêmeas iniciaram a atividade de postura. O pico de fêmeas em atividade ocorreu às 15:00 horas. A luminosidade variou durante o dia e apresentou 2 picos mais evidentes, um às $11: 30$ horas (o maior) e outro às 13:30 horas (que coincidiu com o pico de temperatura). No segundo dia estudado (20 de abril de 1979 - Fig. 4b), o píco de temperatura foi às 15:00 horas e logo depois as fêmeas iniciaram a postura. O pịco de fêmeas em atividade ocorreu às 16:00 horas. A luminosidade apresentou 2 picos mais acentuados, um às 15:00 horas (o maior), que coincidiu com o pica de temperatura, e outro às 11:30 horas. No terceiro dia estudado (9 de maic de 1979 - Fig. 4c) houve um platô de temperatura das $13: 30$ às 14:00 horas e ime diatamente após as fêmeas iniciaram a postura. O pico de fêmeas em atividade de postura ocorreu às 16:00 horas. A luminosidade apresentou 3 picos e o menor deles coincidiu com $\alpha$ pico de temperatura às $14: 00$ horas. No quarto dia estudado (25 de maio de 1979 Fig. 4d) houve um platô de temperatura das $15: 00$ às $15: 30$ horas e no início deste platô, as fêmeas iniciaram a atividade de postura. O pico de fêmeas em atividade de postura ocorreu às $16: 00$ horas. A luminosidade apresentou

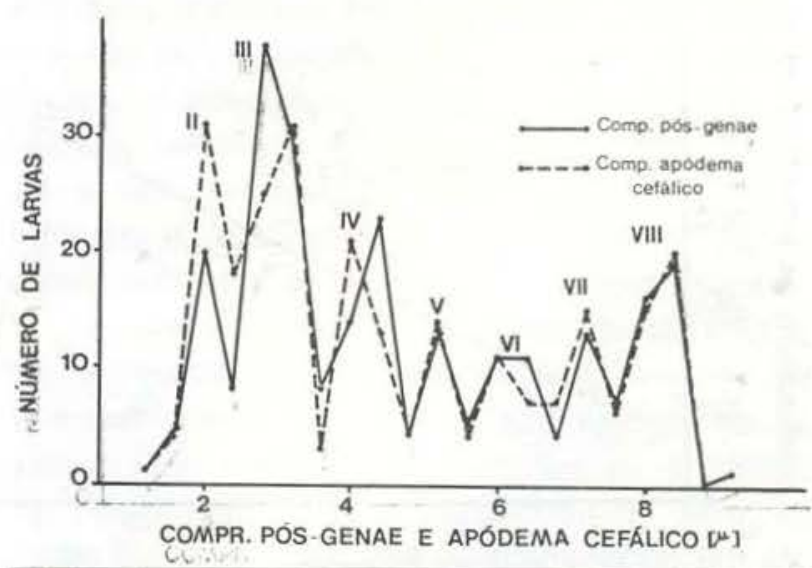

Fig. $3 a-$ Distribuiçẫo de freqüência do comprimento da pós-genae e da distância entre os apódemas cefáli$\cos$ das larvas de $\mathbf{S}$. fulvinotum. (") 0 1. estágio foi obtido por criação dos ovos no laboratório. 
um pico às $11: 30$ horas. No quinto dia de observaçōes (8 de junho de 1979 - Fig. 4e), houve um platô de temperatura das 13:30 às $14: 30$ horas e às 14:30 horas as fêmeas iniciaram a atividade de postura. O número de fêmeas em atividade formou um platô das 16:00: às $16: 30$ horas. A luminosidade variou bastante, formando 5 picos durante o dia e às 10:30 horas houve o maior pico de luz. Em todos os dias de observações, as atividades das fêmeas findaram às 18:00 horas, quando a luminosidade aproxima-se de zero. A umidade relativa do ar não variou, permanecendo sempre a $100 \%$ no criadouro.

As fêmeas aproximam-se do local escolhido para ovoposição e a uma distância de aproximadamente $30 \mathrm{~cm}$ do substrato aglomeram-se em revoada, onde permanecem voando rápido em pequenos percursos sinuosos (Fig. 5 a). Dessa revoada, cada fêmea faz mergulhos freqüentes até o substrato, batem o final do abdomen, depositam os ovos e retornam ao aglomerado de fêmeas em revoada. Este ato, desde o mergulho até o retorno à revoada, ocorre em frações de segundos, pois apesar da água estar correndo velozmente sobre o substrato, as fêmeas imediatamente retornam à revoada, sem que sejam transportadas pela água. Em cada mergulho a fêmea deposita um ou mais ovos, pois executa muitos mergulhos durante o tempo que permanece em revoada de ovoposição. Algumas fêmeas dissecadas continham 320 ovos, em média, nos ovários.

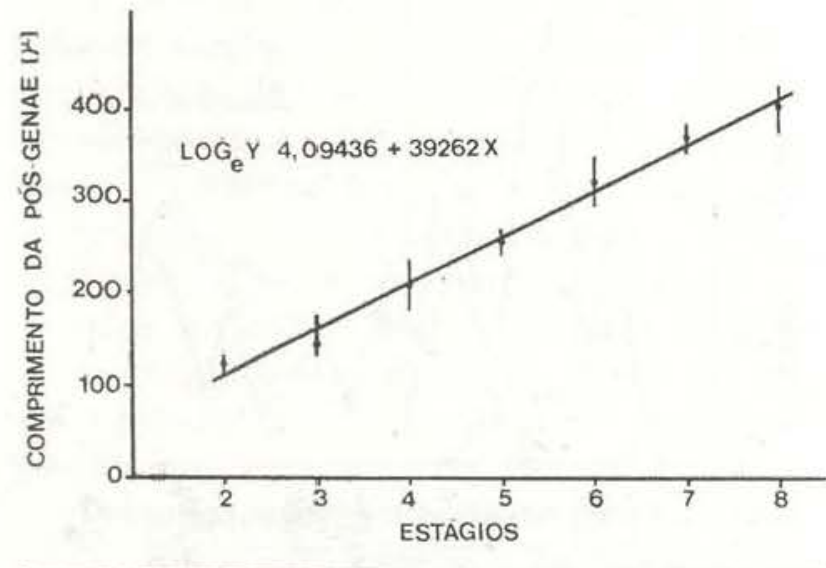

Fig. $3 b-$ Média \pm desvio padrão do comprimento da pós-genae dos 7 últimos estágios larvais de $\mathbf{S}$. fulvinotum.

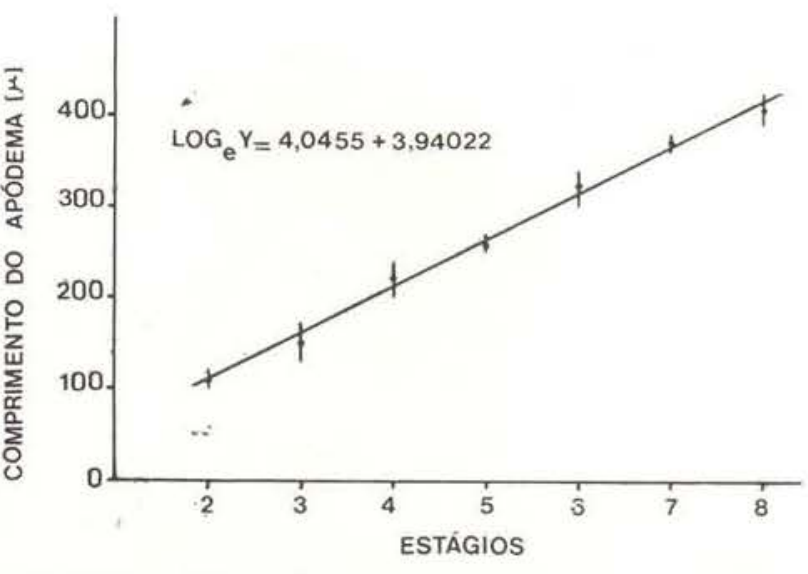

Fig. $3 c-$ Média \pm desvio padrão da distância entre os apódemas cefálicos dos 7 últimos estágios larvais de $\mathbf{S}$. fulvinotum.

Geralmente as fêmeas depositam seus ovos em folhas, gravetos, troncos ou outros garranchos presos na correnteza (Fig. 5b) e mais raramente em pedras ou casinhas de Hydropsychidae (Trichoptera). Esses substratos escoIhidos estão na superfície sendo respingados pelc borbulhamento da água que encontra alguns obstáculos, ou submersos por uma peque na camada de água que eventualmente cobre o substrato. As fêmeas não foram observadas depositando em substratos secos, mesmo que eles estivessem próximos da superfície, e sempre encontrou-se substratos muito próximos de um local do igarapé onde havia maior turbulência de água.

Os ovos são depositados juntamente com uma substância gelatinosa transparente que os gruda ao substrato, o qual, no final da postura. fica completamente coberto por uma massa de 3 ou 4 camadas de ovos sobrepostos, o que dá uma coloração branca opaca, facilmente visível em contraste com as cores escuras do substrato (Fig. $5 \mathrm{c}$ ). Na figura 6 vemos a seqüência do desenvolvimento da larva dentro do ovo. Seis horas após a postura, os ovos apresentam-se de cor marrom clara, mas ainda são opacos. A cor marrom acentua-se gradativamente, a parede vai se tornando transparente e este processo segue até 35 horas após a postura, quando a diferenciação da região anterior (marrom escura) e posterior (branca) da larva dentro do ovo torna-se visível. A 78 horas após a postura, as manchas oculares são 
visíveis na região da cabeça da larva e com 86 horas de incubação vê-se o rebento do ovo ("egg burster"). A eclosão inicia-se 96:45 horas após a postura e a 113 horas de incubação todas as larvas já eclodiram. A fig. $5 \mathrm{c}$ mostra a massa de ovos poucas horas antes da eclosão das larvas e na fig. 5 d vê-se as larvas de primeiro estágio presas em uma teia por elas fabricada.

Logo após a eclosão, as larvas movimentam-se ativamente na solução gelatinosa que cobre as cascas dos ovos; elas produzem suas teias, movimentando-se em direção ao local onde a correnteza e o borbulhamento (turbulência) da água são mais acentuados. No laboratório, no vasilhame experimental, elas se aglomeram nas proximidades da pedra da bomba de ar e no criadouro natural, a grande maioria das larvas fixam-se na pedra da queda d'água, ou em folhas presas próximas da queda. Nestes locais elas fazem suas mudas passando por 8 estágios larvais e pupa.

A distribuição de freqüência dos comprimentos das pós-genae e das distâncias entre os apódemas cefálicos das larvas indicaram a existência de 7 estágios larvais, porém as larvas do primeiro estágio não foram incluídas nestes dados, porque foram obtidas no laboratório por incubação dos ovos; assim, 8 são os estágios larvais de $S$. fulvinotum. As larvas de primeiro estágio foram separadas das demais pelo seu pequeno tamanho e pela presença do rebento do ovo ("egg burster"). O comprimento do corpo variou consideravelmente. não se prestando para uma separação precisa dos estágios larvais.

Os logarítmos naturais das médias \pm desvio padrão dos comprimentos das pós-genae e das distâncias entre os apódemas cefálicos foram confrontados com o número dos estágios larvais, gerando as respectivas linhas de regressão: Pós-genae $-\log Y=4,09436+$ $3,9262 \times$ (Fig. 3b); Apódema cefálico - log $Y=4,0455+3,94022 \times$ (Fig. 3c). A tabela 1 mostra a média do comprimento da pós-genae, do apódema cefálico e do corpo dos 7 últimos estágios larvais de $S$. fulvinotum, como também a taxa de crescimentơ entre estes estágios.

\section{DISCUSSÃo}

Processos fisiológicos e padrões comportamentais de insetos são afetados por fatores climáticos e trocas horárias nas propriedades físicas da atmosfera (Varley et al., 1973). Peterson \& Wolfe (1956) atribuiram mudanças na atividade de simulídeos a 4 variáveis: umidade relativa do ar, temperatura, velocidade do ventu e intensidade da luz. Outros fatores, como mudanças na pressão barométrica, podem também ser importantes. Uma diminuta flutuação na pressão barométrica, associada com a zona de nuvens de cúmulus, parece induzir atividade de vôo em simulídeos (Wellington, 1974).

O termo microclima, segundo Sorre (1961), é aplicável estritamente para a atmosfera de um espaço restrito mais ou menos ou rigorosamente cercado e completamente protegido dos fatores do clima local. A cobertura de uma floresta intercepta pancadas de chuvas, reduz a quantidade de radiação solar que alcança o chão, baixa a temperatura do ar e aumenta a umidade relativa. Também reduz o vento, permite acumulação de umidade estagnada no ar e diminui a taxa de evaporação perto do chão (Read, 1977). Estas são as condições encontradas no local onde as fêmeas de $S$. fulvinotum ovipõem, em substratos na superfície de igarapés de águas pretas, que correm sob a mata primária tipicamente equatorial úmida, próximos de pequenas quedas d'água. As fêmeas iniciaram a atividade de postura quando a luminosidade decresce imediatamente após o pico máximo de temperatura do dia. A temperatura foi aqui evidenciada como um estímulo para as fêmeas iniciarem a postura (Fig. $4 a, 4 b, 4 c$, $4 d$, e 4 e). A umidade relativa do ar, às proximidades do criadouro, parece não ter influência como estímulo, pois essa se mantém constante. A luminosidade variou bastante durante o dia e parece que a intensidade da ovoposição é inversamente relacionada aos valores de luminosidade, influenciando no fim da atividade de postura, quando se aproximou de zero, às 18:00 horas. As fêmeas permaneceram em atividade de postura por um tempo de 3 horas no mínimo e $41 / 2$ horas no máximo. A ovoposição ocorreu somente durante a tarde. Com os dados deste trabalho é possível determinar o 
intervalo de horas, o pico, o local e o substrato onde as fêmeas de $S$. fulvinotum vão executar a ovoposição. Isto possibilita o controle da populaçằo destes dípteros por fumigação sem alterar por demasia o ambiente. O S. fulvinotum não tem importância médica ou veterinária e nunca encontrado atacando o homem ou outro animal, mas se estes fatores ambientais influenciam também a ovoposição de outras espécies de Simulium que têm importância constatada, então tem-se um meio eficiente de controlar a população destes dípteros.

Observou-se que em trechos do igarapé onde a mata foi parcial ou totalmente derrubada, as fêmeas de $S$. fulvinotum não foram en-

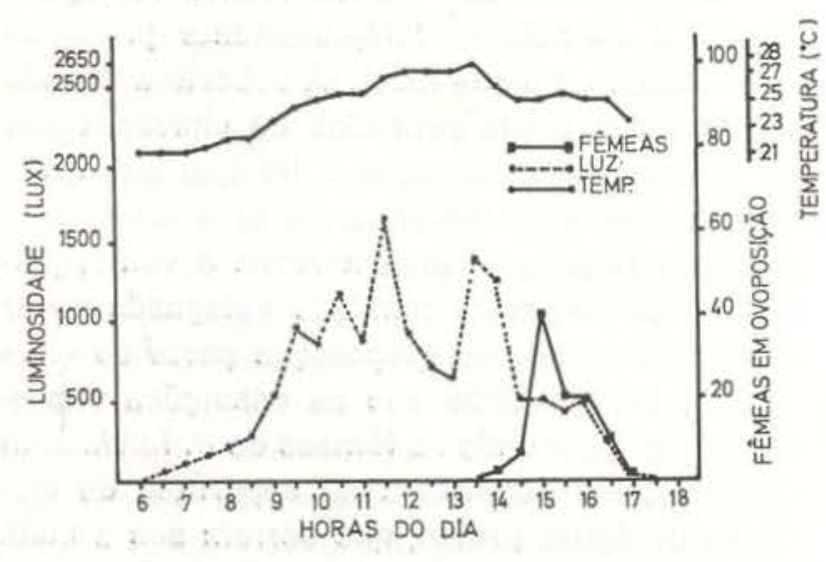

Fig. $4 \mathrm{a}-$ Número de fêmeas de $\mathbf{S}$. fulvinotum em ovoposiçẫo, temperatura e luminosidade no dia 2 de abril de 1979. Manaus, Amazonas, Brasil.

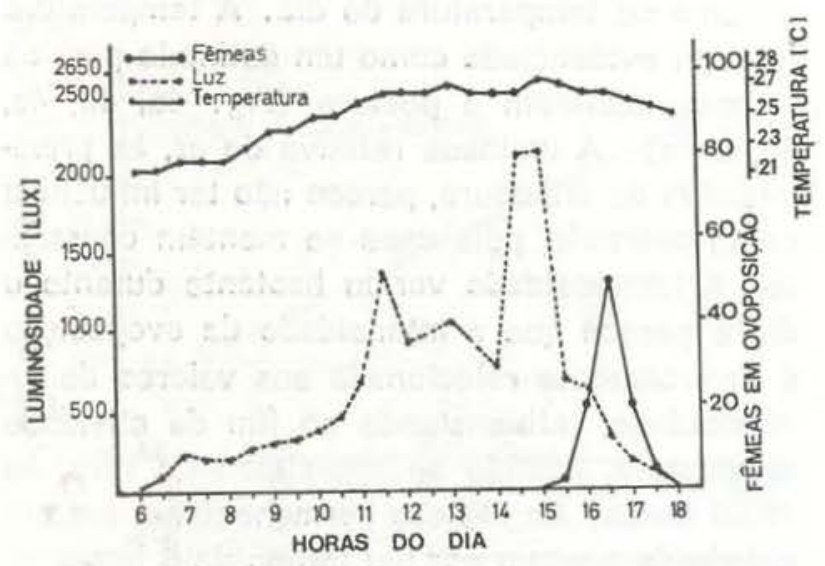

Fig. $4 \mathrm{~b}$ - Número ce fêmeas de $\mathbf{S}$. fulvinotum em ovoposição, temperatura e luminosidade no dia 20 de abril de 1979. Manaus, Amazonas, Brasil. contradas ovipondo, apesar de larvas terem sido encontradas em pequenas quantidades.

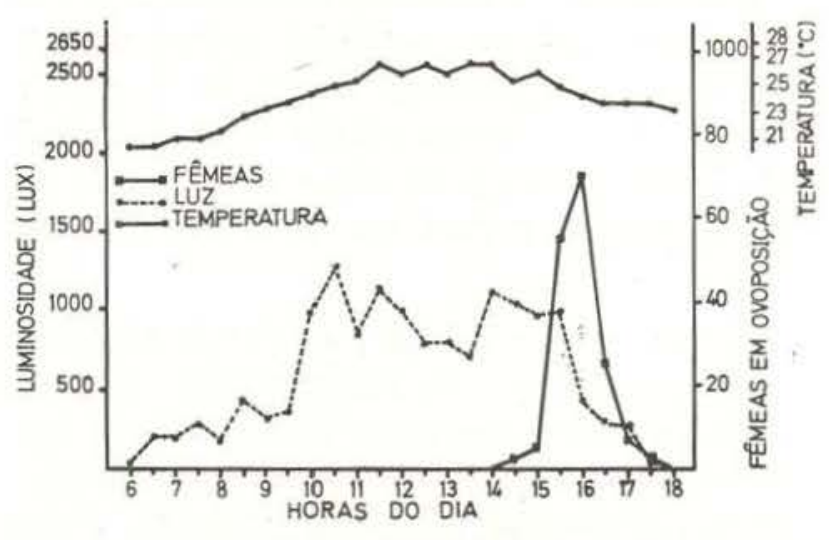

Fig. $4 \mathrm{c}$ - Número de fêmeas de $\mathbf{S}$. fulvinotum em ovoposiçäo, temperatura e luminosidade no dia 9 de maio de 1979. Manaus, Amazonas, Brasil.

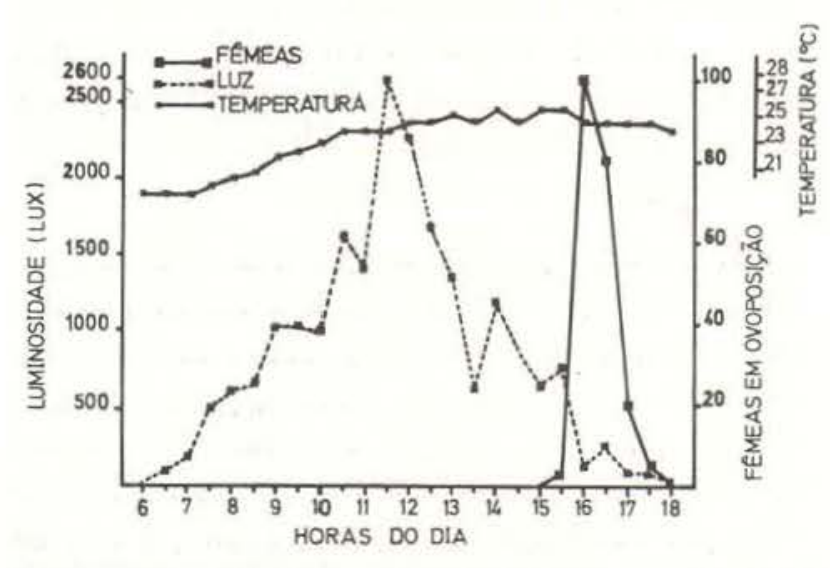

Fig. 4d - Número de fêmeas de S. fulvinotum em ovo. posição, temperatura e luminosidade no dia 25 de maio de 1979. Manaus, Amazonas, Brasil.

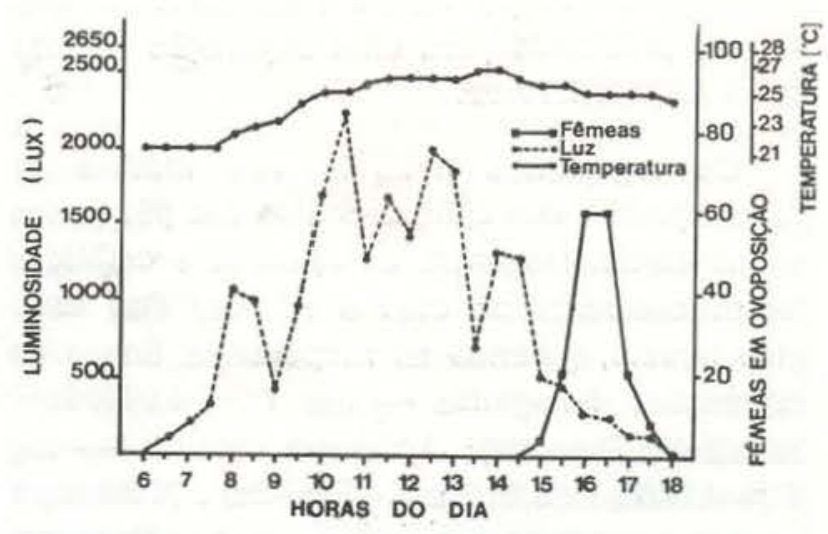

Fig. $4 \mathrm{e}-$ Número de fêmeas de S. fulvinotum em ovoposiçăo, temperatura e luminosidade no dia 8 de junho de 1979. Manaus, Amazonas, Brasil. 

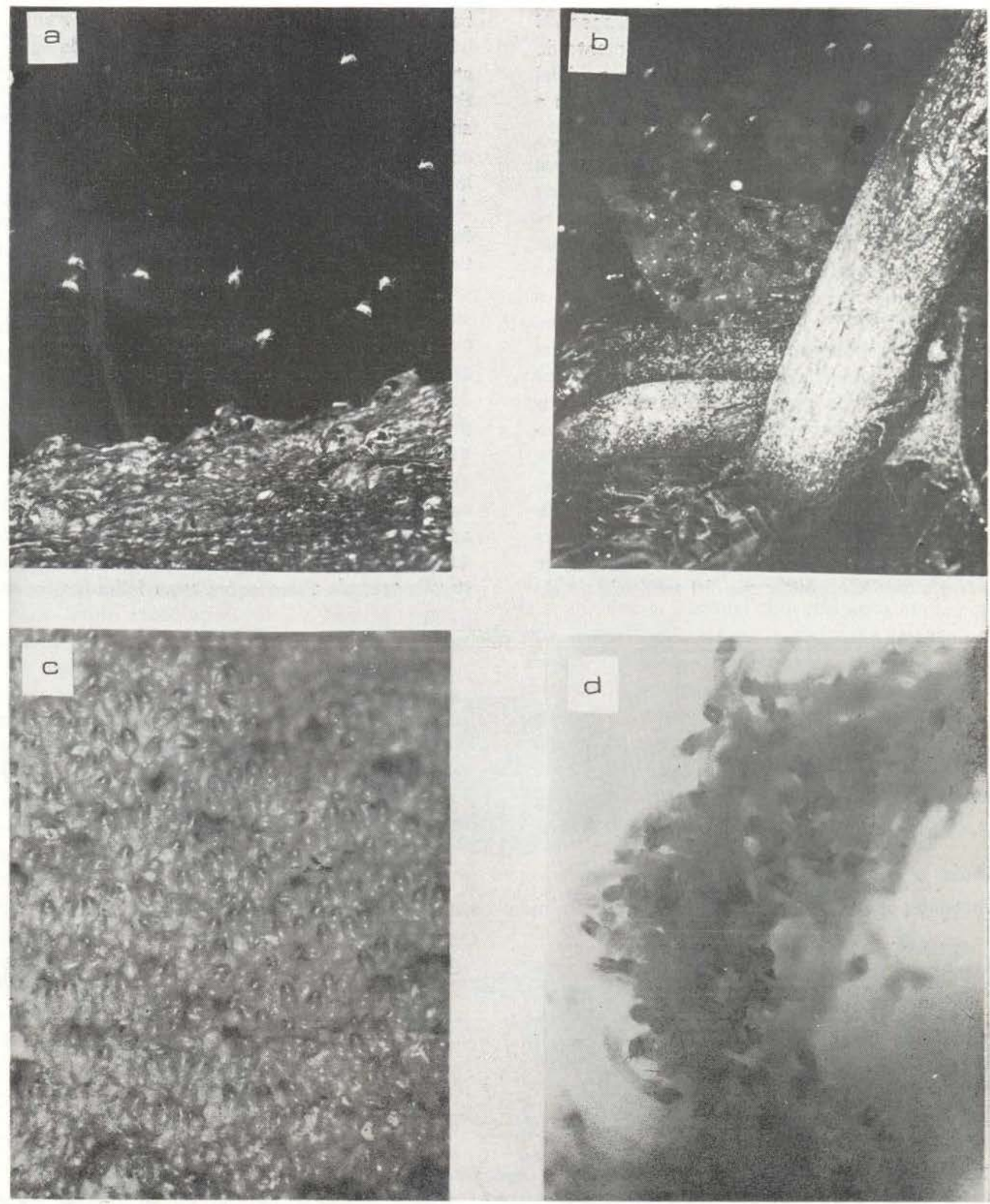

Fig. 5 - a) Fêmeas de S. fulvinotum em revoada de ovoposição a alguns centímetros da superfície do igarapé. b) Fêmeas em ovoposição, garranchos presos na superfície do igarapé e manchas brancas de ovos depositados pelas fêmeas. c) Massa de ovos de S. fulvinotum poucas horas antes da eclosåo. d) Larvas de $10^{\circ}$ estágio de $\mathbf{S}$. fulvinotum presas em uma teia. 
Durante todos os meses do ano é possivel encontrar qualquer fase do desenvolvimento do $S$. fulvinotum em um criadouro, porém no final da época chuvosa ou no final da época seca a população diminui consideravelmente.

Davies \& Peterson (1956) comentaram os diferentes comportamentos de ovoposição dos simulídeos. Os gêneros primitivos Prosimulium e Cnephia ovipõem usualmente batendo o abdômen na superfície da água, depositando um ou mais ovos de cada vez e pairando sobre a superficie, voando livremente. Alguns membros destes gêneros também depositam seus ovos sobre superfícies sólidas. Afirmaram os referidos autores que o depósito de ovos na água com o inseto voando é comum entre certas espécies do gênero Simulium em Ontario, Canadá, e em outras partes, porém, documentaram que uma pequena diferença deste com. portamento foi observado em S. euryadminiculum e S. pictipes e outros. Os insetos pairam sob:e superfície sólida que foi molhada ou co- berta por uma fina camada de água corrente, batem o abdômen rapidaniente através da água até a superfície e depositam um ou mais ovos. Este comportameno pode ocorrer sobre pedra, areia ou vegetação. S. decorum deposita ovos sobre madeira, que está sendo respingada, cimento ou vegetação, em locais bem protegidos do vento, de áreas secas e da luz do sol ou de forte luz indireta. S. pictipes ovipõe sobre água turbuienta, faces de pedras lisas, fora do alcance do vento. S. vittatum mostrou preferência por linhas de vegetação, embora deposite ovos livremente na água turbulenta, madeira, cimento ou pedras onde a vegetação fa!tava. S. venustrum, para Davies \& Peterson (1956), parece ser a espécie mais especialızada dentre as que eles estudaram depositando ovos exclusivamente sobre substratos verdes, embora na auséncia de vegetação, algumas podem depositar os ovos na água enquanto voam. Wenk (19も5) observou que fêmeas de Boophthora erythrocephala voam sobre uma folha que está

\section{INCUBAÇĀO DOS OVOS DE Simulium fulvinotum}

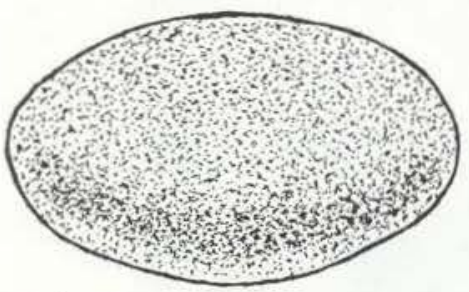

Após a postura

branco opaco

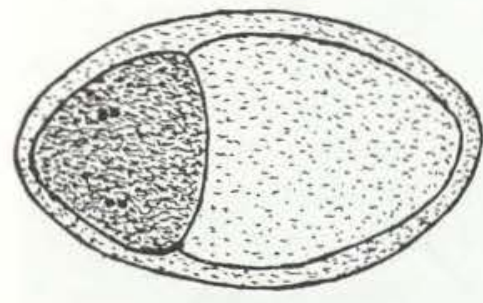

78 horas após a postura marron transparente

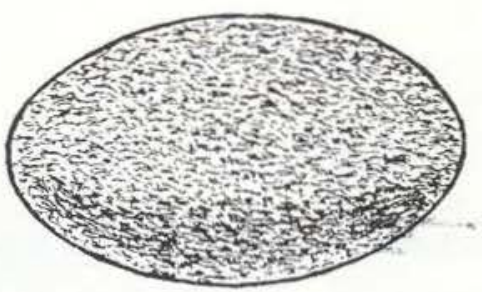

6 horas após a postura marron claro opaco

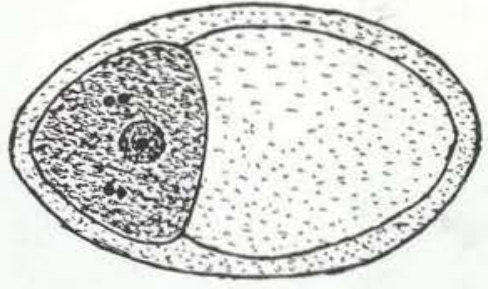

86 horas após a postura

marron transparente

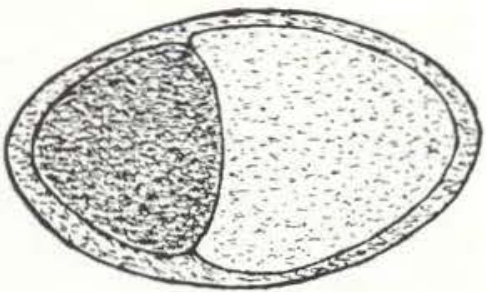

35 horas após a postura marron transparente

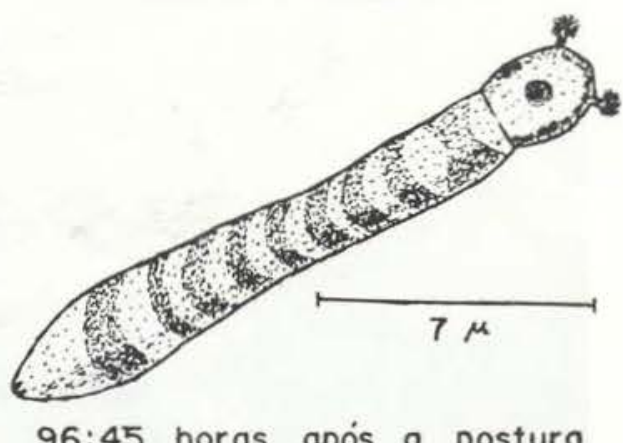

96:45 horas após a postura eclosāo

113 horas após a postura, todas as larvas eclodiram 
flutuando na superfície da água, pousam e movem-se lentamente para o lado inferior da folha. Depcsitam ovos em grandes grupos sob a água, sem serem molhadas. Ainda fêmeas de certas espécies depositam ovos sobre substratos de certas cores: branco, amarelo e verde (Davies, 1978). As fêmeas de S. fulvinotum apresentam comportameto semelhante ao de $S$. euryadminiculum $\Theta S$. pictipes, citado por Davies \& Peterson 1956. Apresentam preferência por substratos marrom-escuros, como folhas secas, pedias gravetos, raizes e ainda casinhas de Hyciropsychidae (Trichoptera). Os locais prefericuos para ovoposição estão protegidos da luz e do vento por qualquer tronco ou plantas próxımos da superfícıe, mas eventualmente algumas fêmeas ovipõem em locais mais abertos.

Vários autores estudaram o número de estágios larvais de simulídeos e encontraram uma variação de 4 a 9 estágios. Ross \& Merritt (1978) listaram os autores e o número de está. gios que eles encontraram em Simuliidae e somente Smith (1969 apud Ross \& Merritt, 1978) encontrou 8 estágios larvais. Os demais acharam espécies com 4, 6, 7 e 9 estágios larvais, sendo que 7 estágios é o número mais comumente encontrado. No presente trabalho, detectou-se 8 estágios larvais em S. fulvinotım. Ross \& Merritt (1978) propuseram que altas temperaturas diminuem o tempo de desenvolvimento, o número de estágios e o tamanho das larvas em maturidade; contudo as condicões climáticas do criadouro de $S$. fulvinotum não estão sujeitas a grandes variações na temperatura, por isso é mais provável que em condições naturais o número de estágios larvais de $S$. fulvinotum seja sempre 8. Dyar (Apud Wigglesworth, 1972) demonstrou que a largura da cápsula da cabeça de larvas de lepidópteros aumenta em progressão geométrica entre os estágios. Em S. fulvinotum também houve um crescimento da cápsula da cabeça em progressão geométrica e a taxa de crescimento variou para a pós-genae de 1,11 a $1,40 \mu$, para o apódema cefálico de 1,11 a $1,47 \mu$ e para o comprimento do corpo, de $1,08 \mathrm{~mm}$ a $1,67 \mathrm{~mm}$ (Tabela I) .

O conhecimento sobre biologia e ecologia dos simulídeos na região amazônica carece de
TABELA 1 - Taxa de crescimento dos 7 últimos estágios larvais de $\mathrm{S}$. fuivinotum calculados das medidas de pós-genae, apódema cefálico e comprimento do corpo de 548 exemplares

\begin{tabular}{c|c|c|c}
\hline Estágios & Pós-genae & $\begin{array}{c}\text { Apódema } \\
\text { Cefálico }\end{array}$ & $\begin{array}{c}\text { Comprimento } \\
\text { do Corpo }\end{array}$ \\
\cline { 2 - 3 } & Taxa de Cresc. & Taxa de Cresc & Taxa de Cresc. \\
\hline 1 & $*$ & $*$ & $*$ \\
2 & 1,25 & 1,36 & 1,67 \\
3 & 1,40 & 1,47 & 1,42 \\
4 & 1,24 & 1,18 & 1,25 \\
5 & 1,23 & 1,23 & 1,19 \\
6 & 1,16 & 1,16 & 1,15 \\
7 & 1,11 & 1,11 & 1,08 \\
8 & & & \\
\hline
\end{tabular}

(*) - Os dados do 1.0 estágio nảo foram calculados porque as larvas foram obtidas por criaçāo no laboratório.

muitos estudos que devem ser desenvolvidos o mais breve possivel, porque os simuiideos são insetos importantes e na regiäo amazônica atacam a procura de repastos sanguíneo em grandes quantidades, em extensas áreas, chegancio a diminuir a capacidade de trabaltio do homem no campo, além de transmitirem Oncocercose (Rossi et al., 1975), Mansonelose (Cerqueira, 1959) e causarem Sindrome $\mathrm{He}$ morrágica de Altamira (Pinheiro et al., 1974) .

\section{AgRAdeCimentos}

Ao Dr. José Alberto S. Nunes de Melo por ceder parte de seu laboratório para execução dos trabalhos. Ao Instituto Nacional de Pesquisas da Amazônia e Museu Paraense Emílio Goeldi que custearam os trabalhos. A Adelmar Gomes Bandeira, Edmar L. Oliveira, Paulo Celso da S. e Souza e Aluisio Ramos pela leitura do manuscrito e Fátima Leite Gorayeb pelo constante incentivo.

\section{SUMMARY}

Adults of Simulium fulvinotum were found for the first in nature, and their breeding sites are described. Ovoposition behavior is described, and the prefered substrates for egg deposition are identified. S. fulvino- 
tum has 8 larval instars, a number found previously in only one other simuliid, as was determined by the measurement of the postgena and cephalic apotome of 548 larvae. The daily high temperature peak appers to be a stimulus for the initiation of egg-laying. The time of day and duration of oviposition were recorded at natural breeding sites. The incubation period of eggs was determined by laboratory rearing. S. fulvinotum is proposed as a model species for the study of the ecology, biology, and behavior of Amazonian Simulium.

\section{REFERENCIAS BIBLIOGRÁFICAS}

\section{CERQUEIRA, N.L.}

1959 - Sobre a transmissăo de Mansonella ozzardi. Nota 1 e nota 2. Jornal Brasileiro de Medicina, 1: $885-914$

CERQUEIRA, N.L. \& MELO, J.A.N.

1968 - Simuliidae da Amazônia IV) Descrição de Simulium fulvinotum sp. n. (Diptera, Nematocera). Amazoniana, 1 (3): 205-210.

DAVIES, D.M.

1978 - Ecology and behavior of adult black flies (Simuliidae): a review. Quaest. Ent., 14 (1): 3-12.

DAVIES, D.M. \& PETERSON, B.V.

1956 - Observations on the mating feeding, ovarium development, and oviposition of adult black flies (Similiidae, Diptera). Can. J. Zoll., 34: 615-655.

DELLOME FILHO, J.

1978 - Fatores físicos-químicos dos criadouros de Simuliidae (Diptera: Nematocera). Tese apresentada para a obtenção do Título de Magistes Scientiae em Entomologia à Comissão Julgadora do Curso de Pós-graduação do Instituto Nacional de Pesquisas da Amazônia e Fundação Universidade do Amazonas. Manaus, Amazonas, Brasil.

GORAYEB, I.S. \& PINGER, R.R.

1978 - Detecção de predadores naturais das larvas de Simulium fulvinotum Cerq. e Melo, 1968 (Diptera, Nematocera). Acta Amazonica, 8 (4): 629-637.

PETERSON, D.G. \& WOLFE, L.S.

1956 - The biology and control of black flies (Diptera: Simuliidae) in Canadá. Proc. Tenth. Int. Congr. Entomol., 3: 551-564.
PINHEIRO, F.P.; BENSABATH, G.; COSTA JR., D.; MAROJA, O.M.; LINS, Z.C.; ANDRADE, A.H.P.

1974 - Haemorrhagic Syndrome of Altamira. The Lancet, Apr. 13: 639-642.

RASSI, E.; LACERDA, N.; GUIMARĀES, J.A.; VULCANO, M.A.; PEEREZ, J.R.; RAMIREZ, A.

1975 - Preliminary report on a new vector of onchocerciasis in the Americas: Simulium amazonicum (Goeldi, Lutz, 1910 and 1917). Paho Bull, 9: 10-12.

READ, R.G.

1977 - Microclimate as background environment for ecological studies of insects in a Tropical forest. J. Appl. Meteor. 16: 1282-1291.

ROSS, D.H. \& MERRITT, R.M.

1978 - The larval instars and population dynamics of five species of black flies (Diptera: Simuliidae) and their responses to selected environmental factors. Can. J. Zool, 56 (8): 1633-1642.

SMITH, C.D.

1969 - The effect of temperature on certain life stages of Simuliidae. M. Sc. Thesis, University of Durham. Durham. (Apud Ross \& Merritt, 1978).

SOKAL, R.R. \& ROHLF, F.J.

1969 - Biometry. W.J. Freeman and Co., San Francisco. 766p.

SORRE, M.

1961 - La notion de micro-climat. Assoc. Geograph. Franc. Bull., 301/302: 162-169.

WELLINGTON, W.G.

1974 - Black fly activity during cummulus-induced pressure fluctuations. Environ. Entomol., 3: 351-353.

WENK, $P$.

1966 - The biology of blood-sucking Simuliidae (Diptera) the mating blood-sucking and oviposition of Boophthora erythrocephala De Geer in the laboratory. W.H.O., 36: 29p., 3 figs.

WIGGLESWORTH, V.G.

1972 - The Principles of Insect Physiology. 7th ed. Chapman \& Hall, London. 827p.

(Aceito para publicação em 29/05/81) 